\title{
PREVALENCE OF DIABETES MELLITUS AND IMPAIRED FASTING GLUCOSE AMONG HYPOTHYROID PATIENTS
}

\section{Amarawardena WKMG', Mahesh PKB $^{2}$, Siyambalapitiya $\mathbf{S}^{1}$}

${ }^{1}$ Diabetes and Endocrine unit, North Colombo Teaching Hospital, Ragama, ${ }^{2}$ Office of Regional Director of Health Services, Ministry of Health, Colombo.

\section{ABSTRACT}

Background: The association between autoimmune thyroid diseases and autoimmune diabetes is well established. However, the association between type 2 Diabetes and thyroid disease is unclear. Studies conducted on this topic worldwide have revealed varying results. The aims of this study were to assess the prevalence of diabetes and impaired fasting glucose in a group of hypothyroid patients in Sri Lanka and to assess the relationship between severity and etiology of hypothyroidism with diabetes and impaired fasting glucose.

Method: This descriptive (prospective) study was conducted at the Endocrine clinic, Teaching Hospital, Ragama over a period of 12 months, where all the new and follow up patients with hypothyroidism (both overt and subclinical hypothyroid patients) attending the clinic during this study period were included until the sample size is achieved. Interviewer-administered questionnaire was used to obtain relevant data from the patient and from the clinic book. Fasting blood sugar was done for all patients. When FBS $\geq 100 \mathrm{mg} / \mathrm{dl}$, the test was repeated. For patients who had repeatedly elevated FBS $\geq 100 \mathrm{mg} / \mathrm{dl}$, Urine for micro albumin and serum creatinine were also checked. If the urine micro albumin was elevated, the test was repeated after 3 months. The presence of retinopathy was assessed by the ophthalmology team.

Results: Majority of the study population consisted of females (91\%). Mean age of the study population was 44.7 (SD - 12.1). 85.6\% of the patients had overt hypothyroidism and $14.4 \%$ had subclinical hypothyroidism. The overall prevalence of diabetes mellitus among the study population was $15.6 \%$. Prevalence of impaired fasting glucose was $31 \%$. The prevalence of diabetes, impaired fasting glucose as well as dysglycaemia among patients with overt hypothyroidism and the subclinical hypothyroidism not significantly different (p$0.905, \mathrm{p}-0.931, \mathrm{p}-0.982$ ). There was no significance difference between the etiology of hypothyroidism and in the prevalence of diabetes and impaired fasting glucose (p- 0.079 , p- 0.182 respectively). None of the newly diagnosed patients with diabetes had microvascular complications.

Conclusion: Overall prevalence of both overt and subclinical hypothyroidism was not associated with type 2 diabetes mellitus and the severity of hypothyroidism did not have an effect on the development of any form of hyperglycemia. There was no significant association between the etiology of hypothyroidism and in the prevalence of diabetes as well as impaired fasting glucose. Even though the age, the body mass index, the presence of hypertension and the family history were significantly associated with the development of diabetes mellitus, the gender and the sedentary lifestyle did not show a significant association with the development of diabetes in our study population.

Keywords: Type 2 Diabetes mellitus, impaired fasting glucose, dysglycaemia, hypothyroidism, subclinical hypothyroidism.

\section{INTRODUCTION}

The association between autoimmune thyroid diseases and autoimmune diabetes is well established. However, the association between type 2 Diabetes and thyroid disease is unclear. Hypothyroidism has been recognized as an insulin resistant state by various in-vitro and preclinical studies (1-3). Altered metabolism of leptin and adipokines have been implicated in 
such pathology (3). As a result, peripheral muscles become less responsive to insulin, which increases the probability of developing diabetes.

Some studies have documented a higher prevalence of thyroid dysfunction (ranging from 12-16\%) among patients with diabetes (4). Similar studies done in Greek, Saudi Arabia and Jordan have shown a prevalence of $12.3 \%, 16 \%, 12.5 \%$ respectively $(6,7,8,9)$. Another large cross-sectional study concluded that the prevalence of hypothyroidism in patients with type $2 \mathrm{DM}$ was much higher warranting thyroid screening for all the patients with type 2 diabetes (5). One study done in Sri Lanka has shown thyroid dysfunction in $21.1 \%$ of patients with type 2 Diabetes and subclinical hypothyroidism $(9.4 \%)$ as the commonest thyroid dysfunction among this patient population (10).

On the other hand, population-based large Norwegian study revealed no association between type 2 diabetes and hypothyroidism (11). This observation was supported by several other cross-sectional studies $(9,12)$. One small prospective study done in this area also has failed to show any association with type 2 diabetes and hypothyroidism (11).

Although there is a reasonable amount of evidence on the prevalence of hypothyroidism among patients with diabetes, there is only one study that has studied the prevalence of diabetes and impaired glucose tolerance among patients with hypothyroidism. This study done in Bangladesh by Ashrafuzzaman SM et al. has shown a higher prevalence of newly diagnosed diabetes (4.8 vs. $7.01 \%, \mathrm{p}<0.01)$ and impaired glucose tolerance (IGT) (11\% vs. $12.6 \%$ among hypothyroid subjects 13. Although Sri Lanka is a country with a higher prevalence of diabetes, there is very limited data related to the prevalence of dysglycaemia among patients with hypothyroidism. The objective of our study was to assess the prevalence of diabetes and impaired glucose tolerance in patients with thyroid dysfunction in Sri Lankan clinical setup.

\section{METHOD}

This descriptive (prospective) study was performed at the Endocrine clinic, Teaching Hospital, Ragama over a period of 12 months, where all the new and follow up patients with hypothyroidism (both overt and subclinical hypothyroid patients) attending the clinic during this study period were included. Patients who did not consent to participate in the study, pregnant ladies, children aged $<20$ years, patients with other endocrine diseases (other than overt or subclinical hypothyroidism) and patients on diabetogenic drugs were excluded. All patients satisfying the inclusion criteria were recruited and data collection was done until the minimum sample size (sample size of 300) is achieved.

Information was gathered from the patient using an intervieweradministered questionnaire and also from the patient clinic records. Demographic data such as the age, sex, marital status and occupation of the patient as well as the data related thyroid status and blood glucose levels were collected. Patients were categorized into two groups, overt hypothyroidism and subclinical hypothyroidism depending on the thyroid function test at diagnosis. Overt hypothyroidism was defined as having symptoms of hypothyroidism, which was confirmed by TSH above the upper limit of reference range with fT4 below the lower limit of reference range (14). Subclinical hypothyroidism was defined as having TSH above the upper limit of reference range with normal fT4 (14).

Fasting blood sugar was done for all patients. Diagnosis of diabetes and impaired fasting glucose were determined using American Diabetes Association criteria. Data on risk factors for DM (eg. Family history, Sedentary lifestyle) were collected during history taking from the patient. Family history was considered as positive if a participant had a biological member of their family having or had diabetes, living or deceased. Patients were considered as having a sedentary lifestyle if they spend seating $>90$ minutes ${ }^{15}$.

Anthropometric measurements (height and weight) were measured according to the standard methods using calibrated equipment. All these measurements were done by two specially trained diabetes nursing officers at the clinic. Body mass index was calculated by using the standard formula (BMI = weight in kgs/height in meters ${ }^{2}$ ). Blood pressure was recorded as the mean of two consecutive measurements in the sitting position taken 10 minutes apart. Blood pressure of $\geq 140 / 90$ $\mathrm{mm} \mathrm{Hg}$ or the use of antihypertensive drugs were considered as having hypertension.

When FBS $\geq 100$ with the $1^{\text {st }}$ report, the tests were repeated and the patients who had persistently elevated $\geq 100$, Urine for microalbumin and serum creatinine were checked. If the urine microalbumin was elevated, it was repeated 3 months apart. Diabetic nephropathy was defined by the following: Persistent albuminuria (>300 $\mathrm{mg} / \mathrm{d}$ or $>200 \mu \mathrm{g} / \mathrm{min}$ ) that is confirmed on at least 2 occasions 3-6 months apart, the progressive decline in the glomerular filtration rate (GFR), Elevated arterial blood pressure (15). Eye referral was arranged for retinopathy assessment. Laboratory tests were collected by the investigators.

Data were analyzed by Statistical Package for Social Sciences (SPSS) version 17. Bivariate analysis was done using chi square test. Having done the normality testing, association between the development of diabetes and quantitative variables were analyzed using the Mann Whitney U test.

Ethical approval was obtained from the Ethical Review Committee of the Faculty of Medicine, the University of Kelaniya and all the patients were recruited after obtaining informed written consent from the patient. 


\section{Table 1: Association between Diabetes, impaired fasting glucose (IFG), Dysglycaemia(DG) and hypothyroid}

status

\begin{tabular}{|c|c|c|c|c|}
\hline Thyroid status & $\begin{array}{r}\text { Diabetes } \\
\text { N }(\%)\end{array}$ & $\begin{array}{r}\text { No diabetes } \\
\mathrm{N}(\%)\end{array}$ & $\begin{array}{r}\text { Total } \\
\text { N( } \%)\end{array}$ & Association \\
\hline \multirow[t]{2}{*}{$\begin{array}{l}\text { Overt hypothyroidism } \\
\text { Sub-clinical hypothyroidism }\end{array}$} & $\begin{array}{r}40(15.6) \\
7(16.3)\end{array}$ & $\begin{array}{r}217(84.4) \\
36(85.7)\end{array}$ & $\begin{array}{r}257(100) \\
43(100)\end{array}$ & $\begin{array}{r}\mathrm{X}^{2}=0.014, \mathrm{df}=1 \\
\mathrm{P} \text { value }=0.905 \\
\mathrm{OR}=0.918, \mathrm{CI}=0.39-2.28\end{array}$ \\
\hline & $\begin{array}{r}\text { IFG } \\
\mathrm{N}(\%)\end{array}$ & $\begin{array}{l}\text { No IFG } \\
\text { N }(\%)\end{array}$ & $\begin{array}{r}\text { Total } \\
\mathrm{N}(\%)\end{array}$ & Association \\
\hline \multirow[t]{2}{*}{$\begin{array}{l}\text { Overt hypothyroidism } \\
\text { Sub-clinical hypothyroidism }\end{array}$} & $\begin{array}{l}80(36.9) \\
13(36.1)\end{array}$ & $\begin{array}{r}137(63.1) \\
23(63.9)\end{array}$ & $\begin{array}{r}217(100) \\
36(100)\end{array}$ & $\begin{array}{r}\mathrm{X} 2=0.008, \mathrm{df}=1 \\
\mathrm{P} \text { value }=0.931 \\
\mathrm{OR}=1.033, \mathrm{CI}=0.5-2.15\end{array}$ \\
\hline & $\begin{array}{r}\text { DG } \\
\mathrm{N}(\%)\end{array}$ & $\begin{array}{r}\text { No DG } \\
\text { N }(\%)\end{array}$ & $\begin{array}{r}\text { Total } \\
\text { N }(\%)\end{array}$ & Association \\
\hline $\begin{array}{l}\text { Overt hypothyroidism } \\
\text { Sub-clinical hypothyroidism }\end{array}$ & $\begin{array}{r}120(46.7) \\
20(46.5)\end{array}$ & $\begin{array}{r}137(53.3) \\
23(53.5)\end{array}$ & $\begin{array}{r}257(100) \\
43(100)\end{array}$ & $\begin{array}{r}\mathrm{X} 2=0.000, \mathrm{df}=1 \\
\mathrm{P} \text { value }=0.982 \\
\mathrm{OR}=1.007, \mathrm{CI}=0.53-1.93\end{array}$ \\
\hline
\end{tabular}

\section{RESULTS}

There were 300 subjects with overt or sub- clinical hypothyroidism, attending the Endocrine Clinic, North Colombo Teaching Hospital, who were recruited for the study. The majority of the study population consisted of females $(91 \%)$. Mean age of the study population was 44.7 (SD - 12.1). $91.3 \%$ of them were married and $69 \%$ were housewives.

From the study population, $85.6 \%$ had overt hypothyroidism and $14.4 \%$ had subclinical hypothyroidism. The overall prevalence of diabetes mellitus among the study population was $15.6 \%$. Diabetes prevalence among females were $14.3 \%$ (43 patients) in females and $1.3 \%$ (4 patients) in males and this difference was not statistically significant. Only $6 \%$ of them were newly diagnosed as having diabetes mellitus during the study and rests of them were already diagnosed patients with Diabetes. Prevalence of impaired fasting glucose was $31 \%$. Therefore, the prevalence of any form of hyper- -glycemia was $46.6 \%$. The large majority (42) of them had signs of Insulin resistance and had BMI $>23$ and the. Rest of the patients did not have signs of insulin resistance or a positive family history for Diabetes. All the patients diagnosed as having Diabetes were well controlled on oral hypoglycemic.

Overall prevalence of both overt and subclinical hypothyroidism was not associated with diabetes mellitus and there was no statistically significant

\section{Table 2: Association between Diabetes, impaired fasting glucose (IFG) and hypothyroid etiology}

\begin{tabular}{|c|c|c|c|c|}
\hline Hypothyroid etiology & $\begin{array}{r}\text { Diabetes } \\
\mathbf{N}(\%)\end{array}$ & $\begin{array}{r}\text { No diabetes } \\
\mathrm{N}(\%)\end{array}$ & $\begin{array}{r}\text { Total } \\
\text { N( } \%)\end{array}$ & Association \\
\hline $\begin{array}{l}\text { Primary hypothyroidism } \\
\text { Secondary to } 1^{131} \text { therapy } \\
\text { Secondary to thyroidectomy }\end{array}$ & $\begin{array}{r}36(15.7) \\
6(31.6) \\
5(8.7)\end{array}$ & $\begin{array}{r}193(84.3) \\
13(68.4) \\
47(91.3)\end{array}$ & $\begin{array}{r}229(100) \\
19(100) \\
52(100)\end{array}$ & $\begin{array}{r}\mathrm{X}^{2}=5.083 \\
\mathrm{df}=2 \\
\mathrm{P} \text { value }=0.079\end{array}$ \\
\hline & $\begin{array}{r}\text { IFG } \\
\mathrm{N}(\%)\end{array}$ & $\begin{array}{r}\text { No IFG } \\
\mathrm{N}(\%)\end{array}$ & $\begin{array}{r}\text { Total } \\
\mathrm{N}(\%)\end{array}$ & Association \\
\hline $\begin{array}{l}\text { Primary hypothyroidism } \\
\text { Secondary to } 1^{131} \text { therapy } \\
\text { Secondary to thyroidectomy }\end{array}$ & $\begin{array}{r}75(38.8) \\
6(46.2) \\
12(25.5)\end{array}$ & $\begin{array}{r}118(61.2) \\
7(53.8) \\
35(74.5)\end{array}$ & $\begin{array}{r}193(100) \\
13(100) \\
47(100)\end{array}$ & $\begin{array}{r}\mathrm{X}^{2}=3.409 \\
\mathrm{df}=2 \\
\mathrm{P} \text { value }=0.182\end{array}$ \\
\hline
\end{tabular}


difference in the prevalence of diabetes $(p-0.905)$, impaired fasting glucose $(p$ $-0.931)$ or dysglycemia $(\mathrm{p}-0.982)$ in patients with hypothyroidism and in patients with subclinical hypothyroidism (Table 1).

In hypothyroid patients with diabetes, $76.5 \%$ of them had primary hypothyroidism, $\quad 12.8 \% \quad$ had hypothyroidism secondary to radioiodine therapy and $10.6 \%$ had primary hypothyroidism, $12.8 \%$ had hypothyroidism secondary to radioiodine therapy and $10.6 \%$ had developed hypothyroidism following total thyroidectomy. There was no statistical significance difference between the etiology of hypothyroidism (primary, post radioiodine, post thyroidectomy) and the prevalence of diabetes ( $p$ - 0.079) among the patients with hypothyroidism (Table 2). Similarly, there was no statistical significance difference between the etiology of hypothyroidism (Primary, post radio iodine, post thyroidectomy) and the prevalence of impaired fasting glucose (p- 0.182) among the patients with hypothyroidism (Table 2 ).

Table 3 shows the bivariate analysis between selected associated factors with the development of diabetes among patients with overt and subclinical hypothyroidism. A family history $(p=0.019)$, presence of hypertension $\quad(p<0.001), \quad$ BMI $(p=0.011)$ and age $(p=0.001)$ were significantly associated with the diabetes at 5\% significant level.

None of the newly diagnosed patients with diabetes had microvascular complications (retinopathy or nephropathy) at the time of diagnosis of diabetes. Only one patient with preexisting diabetes had microalbuminuria and background retinopathy.

\section{DISCUSSION}

Although there is a suggestion that hypothyroidism could be associated with type 2 diabetes and dysglycaemia, our study did not find a statistically significant relationship with the occurrence of diabetes among patients with hypothyroidism and subclinical

\begin{tabular}{|c|c|}
\hline Predisposing factor & Association \\
\hline Gender & $\mathrm{P}=0.961^{*}$ \\
\hline Family history & $\mathrm{P}=0.019^{*}$ \\
\hline Sedentary lifestyle & $\mathrm{P}=0.603^{*}$ \\
\hline Hypertension & $\mathrm{P}=<0.001^{*}$ \\
\hline Body mass index & $\mathrm{P}=0.011^{+}$ \\
\hline Age & $\mathrm{P}=0.001^{+}$ \\
\hline
\end{tabular}

hypothyroidism. The prevalence of diabetes mellitus and impaired fasting glucose among patients with subclinical and overt hypothyroidism patients attending our clinic were $15.6 \%$ and $31 \%$ respectively. We found no association between the severity of hypothyroidism and the development of hyperglycemia. There was no statistically significance difference between the etiology of hypothyroidism (Primary, post-radioiodine, post thyroidectomy) and in the prevalence of diabetes as well as impaired fasting glucose. Even though Age, sedentary life style and family history were strongly associated with the development of diabetes mellitus, body mass index and hypertension did not show a significant association with the development of diabetes in our study group. Our study did not reveal an increased risk microvascular complications among hypothyroid patients with diabetes.

A study conducted by the University of Kelaniya, the prevalence of diabetes was found to be $20.3 \%$ among males, $19.8 \%$ among females and the prevalence of impaired fasting glucose was found to be $42.2^{16}$. Prevalence of diabetes and impaired fasting glucose in our study population (patients with hypothyroidism and subclinical hypothyroidism) was not higher than the latest figures available for population prevalence in that same geographical area and it is even lower than the general population $\quad(15.6 \%$ and $31 \%$ respectively). Several studies including a large population-based study by Hanne F. Fleiner (HUNT study) has also demonstrated similar results where there was a significant association between type 2 diabetes and hypothyroidism (10, 12). However, controversial results were observed in a study done in Bangladesh by Ashrafuzzaman SM et al. where they observed a higher prevalence of newly diagnosed diabetes (4.8 vs. $7.01 \%$, $\mathrm{p}<0.01)$ and impaired glucose tolerance (IGT) $(11 \%$ vs. $12.6 \%)$ among hypothyroid subjects (13).

Thyroxin deficiency has a direct and an indirect relationship with the development of insulin resistance. Reduced metabolic rate related to thyroxin deficiency leads to progressive weight gain, increasing the insulin resistance of that individual. It also alters the metabolism of leptin and adipokines leading to insulin resistance. However, our study did not reveal any association between the severity of hypothyroidism and the development of hyperglycemia. In literature, none of the studies done in the past identified a significant association between severity of hypothyroidism and diabetes or IFG.

There was hardly any research done in assessing the relationship between the etiology of hypothyroidism (Primary, post radioiodine, post thyroidectomy) and in the prevalence of type 2 diabetes. Since there is no immune contribution in the development of type 2 diabetes, it can be argued that thyroxin deficiency is common to all 3 etiological conditions and has the similar predisposition in developing diabetes. Supporting this theory, we found no significance difference between the etiology of hypothyroidism and in the prevalence of dysglycaemia in our study population.

Age, positive family history, sedentary life style and obesity are well known 
predisposing factors for the development of type 2 diabetes. It is sensible to assume that the excessive weight gain that is associated with hypothyroidism could predispose to diabetes. As expected family history, BMI and age were statistically significantly associated with the development of diabetes mellitus in our study population. In addition, presence of hypertension was also associated with the development of diabetes mellitus. However, sedentary life style, gender and smoking were not associated with the development of diabetes mellitus. Different results were obtained in a Sri Lankan study done by Shyaminda Kahandawa et al, where there was no association identified between body mass index and hypertension and prevalence of thyroid dysfunction in a diabetic population. (10).

There is evidence to suggest that patient with diabetes and hypothyroidism are at a high risk of developing microvascular complications. One Chinese study results indicated that type 2 diabetes patients with proliferative diabetic retinopathy (PDR) had a higher prevalence of subclinical hypothyroidism and suggested routine screening for thyroid function in PDR subjects (17). Another small study done in Netherlands have shown an increased risk of renal impairment among patients with hypothyroidism, which improved with thyroxin replacement therapy (18). However, our study did not reveal any increased risk of retinopathy or renal impairment among hypothyroid patients with diabetes.

\section{CONCLUSION}

The overall prevalence of both overt and subclinical hypothyroidism was not associated with type 2 diabetes mellitus and the severity of hypothyroidism did not have an effect on the development of any form of hyperglycemia. Our study did not find any significant association between the etiology of hypothyroidism and the prevalence of diabetes or impaired fasting glucose. Even though the family history, the presence of hypertension, BMI and age were significantly associated with the development of diabetes mellitus, gender and sedentary life style did not show a significant association with the development of diabetes in our study population.

\section{LIMITATIONS}

We made the assumption that all patients who had family a history of diabetes mellitus and well controlled on oral hypoglycemic drugs as having type 2 diabetes mellitus. Rare forms of diabetes such as MODY were not excluded due to unavailability of the genetic test in Sri Lanka.

\section{REFEERENCES}

1. Dimitriadis G, Parry-Billings $M$, Bevan $S$, et al. The effects of insulin on transport and metabolism of glucose in skeletal muscle from hyperthyroid and hypothyroid rats. European Journal of Clinical Investigation 1997; 27(6): 475483.

2. Dubaniewicz A, Kaciuba-Uscilko $\mathrm{H}$, Nazar K, Budohoski L. Sensitivity of the soleus muscle to insulin in resting and exercising rats with experimental hypo- and hyper-thyroidism. Biochemical Journal 1989; 263(1): 243-247.

3. Cettour-Rose P, Theander-Carrillo C, Asensio C, et al. Hypothyroidism in rats decreases peripheral glucose utilisation, a defect partially corrected by central leptin infusion. Diabetologia 2005; 48(4): 624-633.

4. P. Perros, R. J. McCrimmon, G. Shaw, and B. M. Frier. Frequency of thyroid dysfunction in diabetic patients: value of annual screening. Diabetic Medicine 1995; 12(7): 622-627.

5. Diez JJ, Iglesias P. An analysis of the relative risk for hypothyroidism in patients with type 2 diabetes. Diabetic Medicine 2012; 29: 1510-1514.

6. P. Perros, R. J. McCrimmon, G. Shaw, and B. M. Frier. Frequency of thyroid dysfunction in diabetic patients: value of annual screening. Diabetic Medicine 1995; 12(7): 622-627.

7. Papazafiropoulou A. Prevalence of thyroid dysfunction among greek Type 2 diabetic patients attending an outpatient clinic. Journal of Clinical Medicine Research 2010; 2(2): 75-78.

8. 8.Akbar D. H, Ahmed M. M, Mughales J. A. Thyroid dysfunction and thyroid autoimmunity in Saudi type 2 diabetics.
Acta Diabetologica 2006; 43(1): 14 18.

9. Radaideh A. R. M, Nusier M.K, Amari F.L. et al. Thyroid dysfunction in patients with type 2 diabetes mellitus in Jordan. Saudi Medical Journal 2004; 25(8): 10461050.

10. Shyaminda Kahandawa et al.Prevalence of thyroid dysfunction among type 2 diabetic patients attending the Diabetes Clinic, National Hospital of Sri Lanka. Sri Lanka Journal of Diabetes Endocrinology and Metabolism 2014; 4: 43-48.

11. Hanne F. Fleiner, Trine BjØro, Kristian Midthjell, Valdemar Grill, and BjØrn O. Asvold. Prevalence of Thyroid dysfunction in autoimmune and type 2 Diabetes: the population based HUNT study in Norway. Journal of Clinical Endocrinol Metabolism 2016; 101(2): 669-677.

12. Ishay A, Chertok-Shaham I, Lavi I, Luboshitzky R. Prevalence of subclinical hypothyroidism in women with type 2 diabetes. Medical Science Monitor 2009; 15: 151-155.

13. Ashrafuzzaman SM, Taib AN, Rahman R, Latif ZA. Prevalence of diabetes among hypothyroid subjects. Mymensingh Medical Journal 2012; 21(1): 129 .

14. Shlomo M, Kenneth P, Larsen PR, Kronenberg HM. Williams Textbook of Endocrinology 2013; 12: 618-619.

15. Edward W. Gregg, Silvio E. Inzucchi, Mark E. Molitch, John M.Morton, Robert E. Standards of Medical Care in Diabetes-2015. Diabetes Care 2015; 38: 14-80.

16. MJ Pinidiyapathirage, A Kasturiratne, UK Ranawaka, D Gunasekara, N Wijekoon, K Medagoda et al. The burden of Diabetes Mellitus and impaired fasting glucose in urban the population of Sri Lanka. Diabetes Medicine 2013; 30(3): 326-332.

17. G. R. Yang, J. K. Yang, L. Zhang, Y. H. An, and J. K. Lu. Association between subclinical hypothyroidism and proliferative diabetic retinopathy in type 2 diabetic patients: a case-control study. Tohoku Journal of Experimental Medicine 2010; 222(4): 303-310.

18. J. G. Den Hollander, R. W. Wulkan, M. J. Mantel, and A. Berghout. Correlation between severity of thyroid dysfunction and renal function. Clinical Endocrinology 2005; 62(4): 423-427. 